\title{
Negritude a varejo ou quando uma etiqueta é assimétrica: estratégias necropolíticas no campo das artes
}

\begin{abstract}
Resumo
Neste artigo, tematizamos os modos de (in)existência da negritude no interior do projeto colonizador de produção de conhecimento, arte e cultura na contemporaneidade. Nosso objetivo é o de compreender em que (des)medida algumas produções artísticas, ao tematizar a negritude, são rubricadas por autorias brancas, estas, sustentadas por efeitos de verdade produzidas no campo do fazer artístico. Nossa empreitada elege como objeto de análise a obra "Polvo", produzida em 2013, pela artista plástica Adriana Varejão, e parte do questionamento que se delineia da seguinte forma: quais são as estratégias empregadas pela lógica colonial na manutenção das relações de poder estabelecidas no âmbito das artes, de modo que a existência negra se apague tanto no nível autoral, quanto no nível epistêmico da cultura? A partir de uma proposta teórico-analítica de caráter decolonial, cujas bases, são, necessariamente, um modo de inscrição negra no campo de produção de conhecimento, foi possível compreender que o etiquetamento universal, no campo artístico, se trata de uma espécie de estratégia necropolítica de apagamento da autoria negra no âmbito das práticas estabelecidas no campo cultural e artístico.
\end{abstract}

Palavras-chave: Arte brasileira. Negros - Identidade racial. Etiqueta universal.

\section{Rodrigo Pedro Casteleira}

Doutor em Educação pela

Universidade Estadual de Maringá -

UEM. Professor da Fundação

Universidade Federal de Rondônia -

UNIR.

Brasil

pccasteleira@gmail.com

Jefferson Campos

Mestre e Doutorando em Letras pela Universidade Estadual de Maringá -

UEM. Professor no Centro

Universitário Metropolitano de

Maringá - UNIFAMMA.

Brasil

jeffersongustavocampos@gmail.com

\section{Para citar este artigo:}

CASTELEIRA, Rodrigo Pedro; CAMPOS, Jefferson. Negritude a varejo ou quando uma etiqueta é assimétrica: estratégias necropolíticas no campo das artes. Revista PerCursos, Florianópolis, v. 20, n.44, p. 95 - 111, set./dez. 2019.

DOI: $10.5965 / 1984724620442019095$

http://dx.doi.org/10.5965/1984724620442019095 


\title{
Retail blackness or when a label is uneven: necropolitics strategies in the arts field
}

\begin{abstract}
On this paper we broach the blackness (in)existence manners inside the colonizer project of knowledge production, art and culture nowadays. Our aim is to understand how some artistic production, when broaching the blackness, are initialed by white authorship who are supported by truth effects produced in the art making field. Our endeavor picks out as the object of analysis the masterpiece "Polvo", produced in 2013 by the visual artist Adriana Varejão, and it stems from the question that outlined the following: what are the strategies applied by the colonial logic towards the maintenance of the power relations established on the art scope in order to erase the black existence as far as authorship and cultural epistemic levels are concerned? From an analytical theory proposal of decolonial standpoint whose grounding are, necessarily, a black entry in the field of knowledge production, it was possible to understand that the universal labeling, in the artistic area, is about a kind of necropolitic strategy of black authorship deletion in the scope of stablished practices in the cultural and artistic field.
\end{abstract}

Keywords: Brazilian arts. Black people - Racial identity. Universal label. 


\section{Considerações iniciais}

Neste texto, nosso investimento analítico objetiva, dentre outros intentos, deslocar o fundo para o primeiro plano de algumas obras artísticas elencadas ao longo desta escrita. Dito de um modo outro, visamos, especificamente, compreender em que (des)medida algumas produções artísticas, como as da artista plástica Adriana Varejão, especificamente, a obra "Polvo", produzida em 2013, ao tematizar a negritude, são rubricadas por autorias brancas e, em razão disso, chanceladas como válidas. Além disso, lançamos algumas provocações situadas à luz da noção de "chancela" ou "etiqueta universal" elaborada pela branquitude como definidora do que se pode falar, sob o efeito de "saber verdadeiro" a respeito da arte.

A proposta se alinhava a um constructo epistemológico de natureza decolonial. Assim, comporão parte de nossas reflexões um conjunto de textos que, no geral, visam estabelecer um lugar circunstanciado para o fazer científico aqui aventado. No entanto, algumas obras de caráter "tradicional", se não citadas, serão, ao menos, cotejadas para que se estabeleça, como o corolário do pensamento decolonial afrodiaspórico, uma desobediência epistêmica.

Elencamos, assim, algumas discussões para sustentar a nossa tese de que o etiquetamento universal no campo artístico se trata de uma espécie de estratégia necropolítica, modo de governo pensado por Mbembe (2018). Eis a razão para que nosso investimento analítico recaia sobre o fato de que uma 'etiqueta' ou rótulo, origem daquilo que se pode chamar de "verdade" de uma produção artística, quando escrutinada à luz do pensamento decolonial, aponta para mais um dos modos de gestão da vida negra (neste caso, de sua morte no âmbito da representação e produção no campo do artístico).

O desafio a que nos lançamos se justifica, em especial, pela urgência de se pensar a história do presente à luz de uma visada teórica que singularize não só as dinâmicas sociais, culturais e epistemológicas a que se dedica compreender, como também situe, no 
interior da ordem do discurso acadêmico, os/as cientistas apagados nas posições de sujeito que respondem por essa ordem.

Ante ao exposto, o artigo, na primeira seção, explora o conceito de chancela ou etiqueta universal, delineando suas propriedades de ordem metodológica, a fim de que possamos situar nossa tese que identifica esse conceito como suleador ${ }^{1}$ para a compreensão de um funcionamento político das estratégias de gestão da morte do povo negro, no caso em tela, no âmbito da autoria e produção de verdade na ordem das produções artísticas.

Na sequência, nos debruçamos sobre a obra de Varejão (2018), descrevendo o processo estratégico de apagamento da crítica à produção racializada da arte. Muito mais do que criticar a obra da artista, nos interessa apontar um caso exemplar em que a crítica estabelecida pela branquitude responde, apenas, ao esperado para o campo das formas de validação da etiqueta universal sobre a qual a representação não branca não passa de uma existência mínima (LAPOUJADE, 2017).

\section{Etiqueta universal ou chancela? Estratégias necropolíticas}

As categorias de definição do que é cognoscível no âmbito das ideias, portanto, do conhecimento, remontam aos saberes ocidentais, eurocentrados e consequentemente branco (SANTOS; MENESES, 2010). Assim, quando voltamos nosso olhar para a arte e para o artístico, não escapamos a esse mesmo aval semântico. Não é incorreto, desse modo, afirmar que aquilo que entendemos já validado sob ou com o sentido de arte fora instituído por uma espécie de chancela artística, efeito que, neste trabalho, delineamos conceitualmente como etiqueta universal. Santos e Meneses (2010), nesse sentido, são elucidativos quando lembram que o contexto multifacetado da composição sociopolítica

\footnotetext{
${ }^{1}$ Aqui o termo remete às discussões fincadas em convenções de que o Norte, tanto dentro da cartografia como de uma estrutura paradigmática, acaba por imprimir em existências do sul do mundo uma noção outra: a de ser/estar à margem. Paulo Freire (1992) pensa o termo sulear como modo de constituir resistência ao norteamento sob conotações ideológicas marcadas no/pelo sul, revelando um rumo e caminho outros ao mesmo tempo em que se posiciona contra um sistema vigente caucasiano eurocentrado.
} 
contemporânea apenas se solidificou em razão de um projeto de universalidade que, hoje, atende pelo nome de ciência moderna e é o algoz de toda e qualquer tentativa de produção de conhecimento que escape ao aparato institucional que a mantém.

Não significa dizer, portanto, que não houve ou não há outra via epistemológica além daquela que se estabeleceu, sob diferentes regimes de verdade, como ordenadora dos modos de validação da verdade científica. No entanto, não se pode negar o efeito epistemicida (SANTOS; MENESES, 2010) dessa institucionalização da verdade científica ocidentalizada sobre os saberes locais e, por consequência, aqueles que a produziram ou a produzem. Apoiada na trajetória político-epistemológica de feministas negras, Ribeiro (2019) é certeira ao levantar a hipótese de que, nesse sentido, é apenas à luz de uma marcação do "lugar de fala" dos produtores de saber atuantes fora da normatização hegemônica que será possível entender as diversas realidades coexistentes na ordem dos discursos e dos sistemas de saberes.

Do ponto de vista social e identitário, chamamos a atenção para o fato de que ultrapassar o ferrolho da hegemonia da ciência universal, significa liberar espaço (no sentido literal da palavra) para que os diferentes participantes do processo de produção de conhecimento, bem como as diferentes pessoas inscritas nas práticas artísticas, possam entrar na ordem dos discursos validada como verdadeira, pois, "[...] tomar posición en su compleja trama, supone satisfacer ciertas exigencias que califican y autorizan para ello" (EMMANUELE, 2014, p. 313). Daí que, quando discutimos a noção de lugar de fala, não nos restringimos, "apenas", à busca pelo direito à palavra, por enunciar, por pronunciar-se - até porque, "o lugar social não determina uma consciência discursiva sobre esse lugar" (RIBEIRO, 2019, p. 69) - mas à exigência da validação dos mecanismos que fazem da voz dos subalternizados, um discurso de saber validado. Por isso concordamos com Emmanuele (2014, p. 314, grifo da autora), quando esta afirma que "desanudar Verdades que operan como modelo y modelos que ofician como Verdad, abre senderos ya no de relaciones de sentido sino de relaciones de fuerza".

Desse modo, não se trata de uma substituição por um sinônimo, mas de uma política, ao menos, honesta, e orquestrada para dar validade às produções de si na ordem 
dos discursos validados sob uma etiqueta (não mais universal, mas) local, com vistas a atualizar o universal como sendo produto de um conjunto complexo, heterogêneo e emaranhado de sistemas de saberes e de práticas que, de fato, alcançam a multiplicidade de fenômenos concretos do/no mundo real. Aliás, deve-se lembrar que essa estratégia em nada se distancia daquela que opera a ordem da verdade das coisas no tempo presente e, por isso, é a responsável (na verdade, os seus mantenedores) do mesmo modo com o qual a branquitude cria a noção de si dentro do ser universal: sempre tratado como o referente do discurso verdadeiro da ciência, isso porque,

en términos generales todas las denominadas sociedades científicas custodian, vigilan y controlan a perpetuidad, determinada región discursiva con sus prácticas sociales concomitantes y sus reglas de habitación que delimitan a sus calificados parlantes. (EMMANUELE, 2014, p. 316)

Trata-se, então, de entender a noção de etiqueta ou chancela como o discurso verdadeiro, aquele que garante ao sujeito a sua existência. A questão central, no entanto, é: quais existências podem ter espaço no interior de uma economia científica da verdade?

Certamente, não são poucas as produções artísticas assinadas por artistas negros e negras. Jorgen (2015), no artigo “Pintores negros: contribuição negra à arte brasileira”, disponível na Platafoma Geledés ${ }^{2}$, faz um compilado de artistas negros (não apresenta artistas negras) que, de modo significativo, sustenta a ideia de haver a existência de produções fora do eixo da branquitude. No entanto, essa existência não parece ser suficiente para ser validada pelos mecanismos "atuais" de verdade na (ciência da) arte. Como bem observou Lapoujade (2017), o que faz com que os fenômenos não sejam observáveis é o fato de eles serem percebidos segundo um ponto de vista cujo foco único é dar sentido àquilo que garante a continuidade do mundo. No que nos interessa, é o mesmo que dizer que aquilo que apaga as existências negras no âmbito da arte e no da

\footnotetext{
${ }^{2}$ Disponível em: https://www.geledes.org.br/pintores-negros-contribuicao-negra-a-arte-brasileiral. Acesso em: 07 out. 2019.
} 
produção de conhecimento são, justamente, os efeitos de verdade sustentados pela etiqueta universal. Essas condições de invisibilidade histórica são, por ora, as engrenagens das táticas de morte epistemológica do sujeito negro enquanto instância produtora de arte.

O termo etiqueta é primeiro discutido por Ishmael Reed (2000) e revela como o recurso de atribuição simbólica de saber verdadeiro é largamente utilizado no universo artístico como instrumento de validação da obra, de quem a produz e sobre o que discute. Não significa que não exista, mas possui uma estrutura demarcadamente racializada quando somente, e tão somente, a branquitude possa escrever, descrever, pintar, dançar, decalcar etc., de modo a jamais ser julgada, ao passo que qualquer pessoa não branca necessariamente seja apontada como cantora negra, pintor cigano, dançarina oriental.

Nossa proposta é piratear o termo e desdobrá-lo a fim de conjecturar uma categoria utilizada para demarcar as produções artísticas e os desdobramentos do processo de etiquetagem. Nosso recorte, primeiro da produção de uma artista brasileira e de uma obra específica, espraia-se para as discussões de etiquetagem social, pertencentes à necropolítica, por exemplo.

Por desdobramento da necropolítica, entendemos a etiqueta como prática de morte simbólica de pessoas não brancas no campo das artes; os usos de elementos não brancos utilizados pela branquitude em sua produção artística e a etiquetação, por parte da branquitude, do que julga como necessário para rotular como, por exemplo, etiqueta negra, etiqueta oriental etc.

Recorremos a Chuck Galli (2009), em seu texto Hip-Hop Futurism: Remixing Afrofuturism and the Hermeneutics of Identity, no qual suscita questões nevrálgicas para (re)pensarmos as produções negras no universo das artes sob a perspectiva de um outro autor negro, Ishmael Reed (2000). Reed escreveu 300 Years of 1984, em que expõe suas críticas sobre as obras de George Orwell e à ideia da existência de uma 'etiqueta negra' para todas as produções das pessoas negras. 
As pessoas podem me definir e até lucrar interpretando o que chama de 'experiência negra' (pense em todos os milhões de produtores, artistas e escritores não afro-americanos que fizeram a interpretação da 'cultura afro-americana' por meio de romances, filmes, música e televisão - tanto que é discutível se a cultura é étnica). A cultura afro-americana, muitas vezes parece, uma terceira herança de todos os américo-europeus. (REED, 2000, p. 236)

Nem todas as produções provenientes de artistas negras/os são, necessariamente, frutos de suas experiências, mas assim são demarcadas por uma espécie de curadoria da branquitude. Parece haver um impedimento conjurado socialmente às pessoas não brancas em ficcionar obras artísticas que não sejam necessariamente as que falem de si. Contudo, o contrário está firmado como passível e possível, tanto que inexistem questionamentos sobre qualquer personagem negro escrito por uma pessoa branca, ao passo que a uma pessoa negra parece não ser possível narrar etnias outras a não ser a que tanja a sua própria existência (GALLI, 2009, p. 28). Nesse momento, segundo Reed (2000), é como se uma terceira herança, a afro-americana, existisse nos Estados Unidos da América de modo quase que orgânico e dotado de orgulho. No caso brasileiro, essa herança fora forjada sob o mito da democracia racial, proveniente da mescla do índio, negro e branco, que significaria um sistema racial sem qualquer barreira, tanto legal como institucional, além de não existirem manifestações de racismo ou mesmo discriminação (DOMINGUES, 2005). Essa postura mítica sustenta as argumentações da branquitude como modo de legitimar a igualdade existente (?) entre ela e as pessoas não-brancas, bem como o da posição universal enquanto paradigma.

Os conceitos referentes à branquitude apoiam-se em Lourenço Cardoso (2017) e Priscila Elisabete da Silva (2017) a fim de localizar as construções históricas e sociais de uma categoria que primou pela categorização, entre outras coisas, da ficção do poder de si. Nesse processo de ficção, as normas de quem pode chancelar quem são criadas. Nesse processo de ficção sobre as demais, as artes são alocadas, são rotuladas e rotulam seus/suas artistas, exceto a própria branquitude. 
No caso brasileiro existe uma similaridade presa ao imaginário quando alguém branca/o, com uma avó ou bisavó negra, Ihe concede um 'pé na senzala'. Essa expressão revela as tentativas de justificar um passado que não está inscrito em seus fenótipos, assim como de ser partícipe de uma ancestralidade negra. Esconde-se, mais uma vez, nas etiquetas brancas da universalidade, as condições de ser o que quiser, até mesmo um não branco, na chamada modernidade (ainda que tutelado pela atitude dita "fraterna").

Esse momento ficcionado como modernidade carrega em seu bojo as classificações e subalternidades dos sujeitos, instaurando as fronteiras entre moderno e colonial.

\begin{abstract}
O longo século XVI, que consolidou a conquista da América e o apogeu dos impérios Espanhol e Português, significou não apenas a criação de uma economia mundial, mas a emergência do primeiro grande discurso do mundo moderno, que inventou e, ao mesmo tempo, subalternizou populações indígenas, povos africanos, muçulmanos e judeus (como argumenta o artigo de Grosfoguel nesse dossiê). Esse é o contexto nascente da modernidade sistematicamente negado nas descrições hegemônicas da modernidade feita a partir da própria Europa (como um locus de enunciação) e também assumido pelos autores pós-coloniais, que tomam o início da modernidade a partir do século XVIII. (BERNARDINO-COSTA; GROSFOGUEL, 2016, p. 18)
\end{abstract}

Tais fronteiras deram subsídios para os desdobramentos futuros/presentes sobre as práticas de racismo científico, islamofobia, segundo os autores supracitados, e que consideramos como parte do processo ficcional de categorizar quem produz no universo da arte.

Se qualquer artista negra/o produz, necessariamente a cobrança é a de que deve falar de si e de suas existências, sem que o mesmo valha para o branco universo, como podemos observar, por exemplo, nas produções da teledramaturgia brasileira da escritora Glória Perez, ao retratar qualquer campo cultural sem nenhuma crítica por tal conduta. A etiqueta branca, vide universal, reforça a fronteira quase palpável da invisibilidade da branquitude, não enquanto falta de percepção de si sobre a racialidade, 
mas, nas palavras de Jorge Hilton de Assis Miranda (2017, p. 56), "como a falta de percepção sobre seus próprios privilégios”. Glória Perez, por exemplo, escreveu sobre culturas muçulmanas, ciganas, indianas, sem qualquer problema frente a sua branquitude ao dispor ficções que não dialogam com sua própria existência étnica.

Os desdobramentos da rotulação ganham conotações outras segundo a inscrição da pele, como discutiremos a seguir, ao analisarmos um caso exemplar desse processo de produções artísticas produzidas por pessoas brancas, que têm por objeto corpos e/ou culturas não brancas.

\section{Cores a varejo: ou de como etiquetar}

A branquitude, de modo sintético, pode ser definida como uma construção ideológica de poder fecunda quando do surgimento do projeto de modernidade eurocentrada, conforme Priscila Elisabete da Silva (2017). O conceito, conforme a autora, carregado de complexidades, demarca suas posições de poder implicando em classificações dos demais sujeitos (não brancos) sob sua perspectiva (branca), além de "vantagens materiais e simbólicas aos brancos em detrimento dos não brancos. Tais vantagens são frutos de uma desigual distribuição de poder (político, econômico e social) e de bens materiais e simbólicos" (SILVA, 2017, p. 27-28).

Essas miradas da branquitude invadem todos os campos dos saberes, entremeando-se a eles e materializando-se nas toxicidades do aparelho do Estado transfiguradas nas molecularidades cotidianas (MOMBAÇA, 2017). Essas molecularidades carregam o campo simbólico da branquitude, mesmo quando esta retrata as não brancas, desdobrando-se nos mais diversos projetos sobre e para as demais pessoas.

Propomos, pretensamente, discutir as propostas de Adriana Varejão, artista plástica brasileira que traz para sua temática, entre outras coisas, a historicidade da formação do povo brasileiro. Essa temática pode ser observada em suas obras de azulejaria ou pintura, mas aqui, nosso foco encerra-se na sua produção chamada "Polvo". 
Junto a ela, somamos uma entrevista concedida pela artista à Revista TPM (2019) e um artigo explicando a proposta de sua produção.

Adriana Varejão retrata em "Polvo" o universo da miscigenação brasileira, sob a captura de matizes das peles anunciadas pela população ao Instituto Brasileiro de Geografia e Estatística (IBGE). Ao todo, 136 definições de tonalidades foram ditas pelas pessoas sobre suas próprias definições em 1976, traduzidas em 33 cores de tinta por Adriana. Além disso, a artista desenvolveu uma instalação com onze autorretratos de si (Figura 01), classicamente pintados em que as cores da pele são escalonadas numa cartela que percorre da mais escura até a mais clara (VAREJÃO, 2018). O que está em jogo nos jogos da 'mestiçagem’? Adriana desenha, e bem, o que está em jogo:

As castas acabavam prevendo, através de mais de cem categorias de mistura, qualquer tipo de miscigenação entre brancos, negros, indígenas e mestiços. As pessoas consideradas "de raça pura" eram reconhecidas como parte da nobreza e, por isso, detinham maior poder econômico e social. Já as mais misturadas aos negros eram aquelas que ocupavam posições menos privilegiadas. (VAREJÃO, 2018, sem página)

Seguindo a perspectiva endo-localizada, a artista é demarcadamente branca, e seus trânsitos pelos universos da arte foram também difíceis segundo a categoria de gênero. Porém, a marca de sua pele não parece ter sido um obstáculo para a aceitabilidade estética de produção, tanto que a etiqueta branca não é questionada, tal como já apontava Reed (2000), quando ela não retrata experiências efetivamente de si, mas é sustentada pela universalidade hegemônica.

A hegemonia, pensando nos conceitos gramiscianos, trata-se de uma "capacidade de direção intelectual, moral e cultural, em virtude da qual a classe ou grupo dominante, ou aspirante ao domínio, consegue ser aceito como legítimo e obtém o consenso da maioria da população" (FERNANDES, 2014, p. 194). Nota-se que essas ficções inscritas, propagadas e aceitas estão em consonância com as estruturas hegemônicas a tal ponto que está como que aceita pela maioria da população, constituindo-se como uma verdade. 
A produção da artista parece revelar essas estruturas hegemônicas quanto ao aceite de suas obras, de modo a fazer valer, nos parece, o funcionamento da cafetinagem estética (ROLNIK, 2018) inconsciente (?), reverberando em seus processos criativos. A etiqueta universal, jamais racializada pelos pares, parece garantir a existência e permanência de um discurso de verdade.

Figura 01 - Parte da obra Polvo, de Adriana Varejão
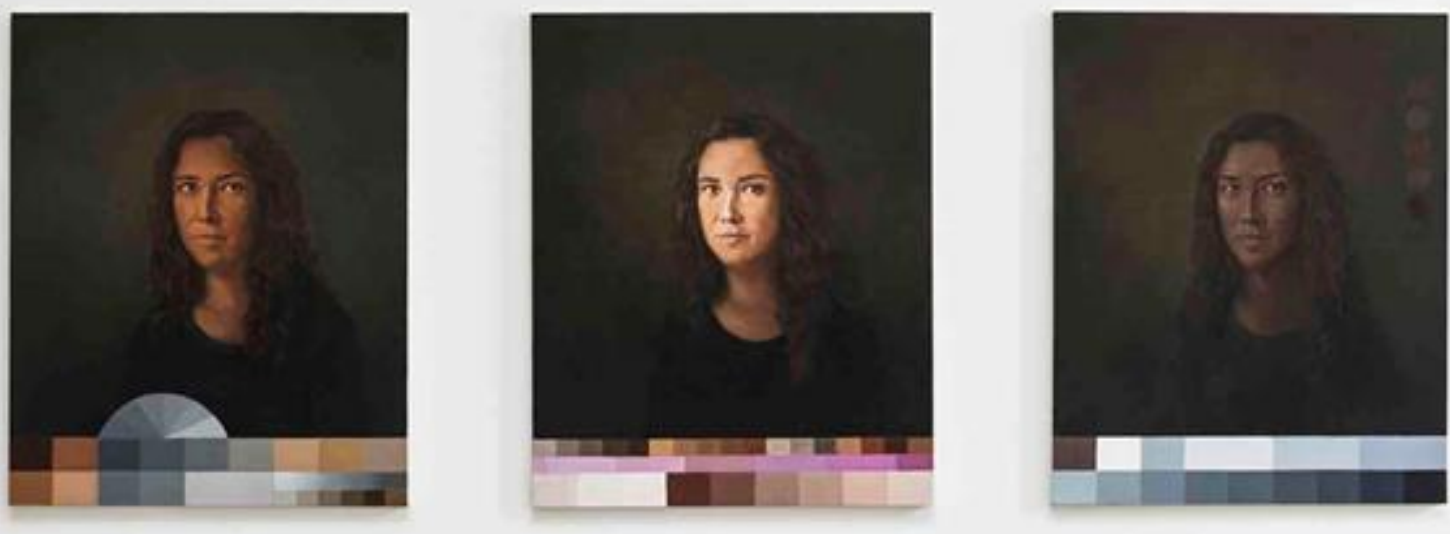

Fonte: Ferreira, 2017.

A artista poderia, por exemplo, pertencer à categoria de branquitude crítica (CARDOSO, 2017), condenando o racismo, percebendo seus privilégios e, concordamos com Cardoso (2017), estar nesse recorte não significa ser homicida. De fato, o posicionamento da artista está nessa perspectiva crítica e balizada no exercício reflexivo de uma sociedade racializada:

Se Polvo mostra como a categoria de raça é subjetiva, o trabalho também desmascara a hipocrisia cotidiana que permeia nossas relações. Vivemos em uma sociedade na qual quanto mais rico, mais branco. A cor vira um dispositivo de poder diário que coloca as pessoas "em seu devido lugar”. (VAREJÃO, 2018, sem página) 
No entanto, seus atributos raciais não representaram problemas para a demarcação social como artista ou mesmo para a seleção sobre o que discutir em suas obras. Não questionamos a habilidade da artista, técnicas ou importância enquanto mulher latina na produção, mas a rotulação de passabilidade e validade na produção, qualquer que seja o objeto de inspiração.

Não é de hoje que a perspectiva racializada de ficcionar a existência de pessoas não brancas existe. Rugendas, por exemplo, foi um pintor alemão que, no século XIX, viajou pelo Brasil retratando os povos encontrados. Várias de suas obras foram levadas aos livros didáticos no século seguinte, sem contextualização de suas produções (TEIXEIRA; PACÍFICO, 2014). A hegemonia, essa espécie de poder invisível, mas materializável, dita os universos estéticos e políticos herdados pelos moldes coloniais, amalgamando-se às possibilidades de tentativas de fuga e inventividades, rendendo-se, sem perceber, ao que gostaria de combater: o fetiche pelo outro.

A materialização desse fetiche dá-se nas produções artísticas quando há uma aparente necessidade de representação, indiferente de quem seja e do que produza. $O$ fetiche está a serviço do consumo, da monetização e de uma nova espécie de colonização estética do outro. Se a obra fala por si e antes de quem a produz, por que mencionamos as autorias de Rugendas, Picassos e Michelangelos? Porque a falácia da grandiosidade do artista esconde a hegemonia euro-branco-centrada e todas as articulações do imaginário que deram sentidos "à instituição de direitos diferentes, para diferentes categorias de pessoas, para fins diferentes no interior de um espaço" (MBEMBE, 2018, p. 38).

As definições de diferença instauram as noções de soberania e esta, por sua vez, significa ocupar, implicando em ocupações que revelam uma articulação engenhosa deslocando a pessoa colonizada para "uma terceira zona, entre o estatuto de sujeito e o objeto" (MBEMBE, 2018, p. 38). Para que a soberania se efetivasse, o espaço é o terreno, a matéria-prima para definir os limites e o princípio de exclusividade recíproca, retomando as análises de Franz Fanon (MBEMBE, 2018). Ninguém indica a 'raça' de Michelangelo ou mesmo a de Adriana Varejão e, a isso, Ishmael Reed, conforme Larson 
(1988, p. 02), chama de preconceito sob o "disfarce do liberalismo: brancos estabelecem padrões diferentes para não-brancos mesmo quando eles estão tentando ser sensíveis".

Aproximamos a noção de soberania à da etiqueta branca por compreender que esta é um desdobramento daquela dentro dos moldes estéticos-políticos, além do posicionamento da soberania ao definir a descartabilidade de quem ela julga como inapta, ainda seguindo as trilhas das discussões de Achille Mbembe (2018). Quando não há o descarte dessa existência entre sujeito e objeto, as articulações colonizadoras gerenciam quem pode retratar quem, quais os limites possíveis e as variações ficcionais do universal em relação ao específico.

\section{Considerações nada finais}

Pensar discussões sobre arte e quem a produz, descoladas de posicionamentos raciais parece figurar como um emblema para aquelas já canonizadas ou produzidas por pessoas que não sejam racializadas. Assim, a obra transcende quem a produziu, ou melhor, a obra fora demarcada como transcendente, em certa medida, pelo valor que representa quando produto de pessoas brancas. Contudo, a obra ganha necessariamente a categoria étnica, racializada, particular, quando produzida por pessoas fora da categoria de branquitude.

Essa categoria é fruto das etiquetas produzidas para chancelar as produções: se a branquitude produz, mesmo que o objeto de produção não seja ela mesma. Temos a etiqueta universal, neutra e regradora do todo, especialmente, porque tem a chancela do saber verdadeiro, instituído pela ciência universal que, como vimos, tem raça e ela não é negra; se a produção é de outras pessoas, como negras ou indígenas, por exemplo, a cobrança é que essas pessoas só possam produzir falando de si e serão demarcadas como uma etiqueta étnica, ou étnico-racial. Desse modo, as produções não universalizadas tornam-se etiquetadas, no mais das vezes, como artefatos culturais o que, no nosso entender, nada mais é, à luz da crítica decolonial, o arremedo da arte. A produção de verdade da branquitude sobre pessoas não brancas figura-se como um elemento plástico 
e recalibrável, sempre em favor da dita universalidade, sempre em favor de uma necropolítica sistêmica e orquestrada.

Quando trazemos as provocações sobre "Polvo", de Adriana Varejão, é mais para ilustrar exemplo dos modos de etiquetagens existentes, do que para atacar o trabalho ou sua autora, em outras palavras, é para dar visibilidade à estratégia necropolítica que, não bastasse o alcance físico, assassinando por bala, fome ou miséria a população negra, se estende, de modo insidioso, pelas vias epistêmicas, esfacelando as condições de possibilidade de as produções artísticas negras se alçarem à categoria de arte ou, ao menos, colocando em questão as produções que tomam a existência negra sob o olhar objetivador da branquitude.

No caso em análise, o posicionamento racializado de Varejão não a impede de deslocar para si as tensões vividas por categorias subalternizadas no Brasil, materializando-os em políticas de morte transfiguradas em estéticas visuais. Esse posicionamento centrado na diferença em relação à existência conota, e muito bem, as castas brasileiras, como a artista diz, mas não apaga, ainda, seu posicionamento centrado na universalidade que, como entendemos, é só mais um número no estrato dessa política científica da verdade.

\section{Referências}

BERNARDINO-COSTA, Joaze; GROSFOGUEL Ramón. Decolonialidade e perspectiva negra. Revista Sociedade e Estado, v. 31, n. 1, p. 15-24, jan./abr. 2016.

CARDOSO, Lourenço. A branquitude acrítica e as críticas. In: MÜLLER, Tânia M. P.; CARDOSO, Lourenço (orgs). Branquitude: estudos sobre a identidade branca no Brasil. Curitiba: Appris, 2017. p. 33-52.

DOMINGUES, Petrônio. O mito da democracia racial e a mestiçagem no Brasil (18891930). In: DIÁLOGOS Latinos n 100. Aahrus: Universidad de Aahurs; Latinoamericanistas, 2005.

EMMANUELE, Elsa. Verdad, política y método. In.: NOVO, Rita (comp.). Michel Foucault: la insumisión reflexiva. 1. ed. Mar del Plata: EUDEM, 2014. p. 311-321. 
FERNANDES, Otair. O conceito de hegemonia na luta contra o racismo no Brasil: a função dos NEABS. [SYN]THESIS, Rio de Janeiro, v. 7, n. 2, p. 191-204, 2014.

FERREIRA, Graziella. A discussão de raça no Brasil na obra de arte "Polvo". Woo Magazine, [S.I.], set. 2017. Disponível em: https://woomagazine.com.br/discussao-deraca-no-brasil-na-obra-de-arte-polvo/. Acesso em: 11 set. 2019.

FREIRE, Paulo. Pedagogia da esperança: um reencontro com a pedagogia do oprimido. Rio de Janeiro: Paz e Terra, 1992.

GALLI, Chuck. Hip-Hop futurism: remixing afrofuturism. the hermeneutics of identity. honor project overview. Rhode Island, 2009. Disponível em:

https://digitalcommons.ric.edu/cgi/viewcontent.cgi?article=1018\&context=honors_project s. Acesso em: 05 jul. 2019.

JORGEN, Negro. Pintores negros: contribuição negra à arte brasileira. Geledés - Instituto da mulher negra. [São Paulo], 08 Jun. 2015. Disponível em:

https://www.geledes.org.br/pintores-negros-contribuicao-negra-a-arte-brasileira/. Acesso em: 07 out. 2019.

LAPOUJADE, David. As existências mínimas. Tradução de Hortencia Santos Lencastre. 1. ed. São Paulo: N-1 edições, 2017.

LARSON, Thomas. Pounding way at racism: review: “writin' is fightin”, by Ishmael Reed. [S.l., 1988] Disponível em: https://www.thomaslarson.com/publications/criticism/88writin-is-fightin.pdf. Acesso em: 07 out. 2019.

MBEMBE, Achille. Necropolítica. São Paulo, SP: N-1 edições, 2018.

MIRANDA, Jorge Hilton de Assis. Branquitude invisível - pessoas brancas e a não percepção dos privilégios: verdade ou hipocrisia? In: MÜLLER, Tânia M. P.; CARDOSO, Lourenço (orgs). Branquitude: estudos sobre a identidade branca no Brasil. Curitiba: Appris, 2017. p. 53-68.

MOMBAÇA, Jota. Rumo a uma redistribuição desobediente de gênero e anticolonial da violência! Disponível em: https://issuu.com/amilcarpacker/docs/ rumo_a_uma_redistribuic_a_o_da_vi. Acesso em: 23 nov. 2017.

REED, Ishmael. "300 Years of 1984": in the Reed reader. New York: Basic Books, 2000. p. 235-246.

RIBEIRO, Djamila. Lugar de fala. São Paulo: Sueli Carneiro; Pólen, 2019. (Coleção feminismos Plurais). 
ROLNIK, Suely. Esferas da insurreição: notas para uma vida não cafetinada. São Paulo: N1 edições, 2018.

SANTOS, Boaventura de Sousa; MENESES, Maria Paula. Introdução. In: SANTOS, Boaventura de Sousa; MENESES, Maria Paula (orgs.). Epistemologias do Sul. 1. ed. São Paulo: Cortez, 2010.

SILVA, Priscila Elisabete da. O conceito de branquitude: reflexões para o campo de estudo. In: MÜLLER, Tânia M. P.; CARDOSO, Lourenço (orgs.). Branquitude: estudos sobre a identidade branca no Brasil. Curitiba: Appris, 2017. p. 19-32.

TEIXEIRA, Rozana; PACÍFICO, Tânia Mara. Relações entre gênero e raça: negritude e branquidade em livros didáticos de história, língua portuguesa e educação física. In: ANPED SUL, 10., 2014, Florianópolis. Anais [...]. Florianópolis: Anped, 2014. p. 01-22.

VAREJÃO, Adriana. Polvo, por Adriana Varejão. In: Revista Philos. Pernambuco, nov. 2018, s/p. Disponível em: https://revistaphilos.com/2018/11/29/polvo-por-adriana-varejao/.

Acesso em: 11 ago. 2019.

Recebido em: 07/10/2019

Aprovado em: 20/12/2019

Universidade do Estado de Santa Catarina - UDESC

Centro de Ciências Humanas e da Educação - FAED

Revista PerCursos

Volume 20 - Número 44 - Ano 2019 revistapercursos@gmail.com 